\title{
Effect of Elevated Temperatures and Thermal Cycles on Self Compacting Concrete Reinforced with Polypropylene Fibers
}

\author{
Deepak G Appaji, Chethan K
}

\begin{abstract}
SCC has been widely adopted in the various applications. Addition of fibers to SCC has shown to increase the strength and concrete durable. Concrete structures are subjected to intense solar radiations and alternating temperatures throughout their lifetime right from the time of casting. The variation in the properties of concrete due to this radiation exposure and thermal cycles of alternating hot and cold temperatures needs to be investigated. The current study presents an investigation on compressive and flexural strength as well as weight reduction in polypropylene fiber reinforced $S C C$ at $100^{\circ} \mathrm{C}$ thermal cycles of 7, 14 and 28 days. Two mixes of concrete namely normal SCC and SCC with mineral admixture (10\% silica fume) are considered. Strength is observed to improve with an increase in thermal cycles while the weight is found to reduce.
\end{abstract}

Keywords - Self Compacting Concrete, Fibers Reinforced Concrete, Polypropylene Fibers

\section{INTRODUCTION}

Concrete is the second most-consumed material after water and is the most commonly used manufacturing material in the world. Concrete is a composite material it includes cement, fine aggregate and coarse aggregate. Frequently additives (chemical \& mineral admixtures) includes mixture to accomplish the desired physical properties of the finished materials. The popularity extensive use of concrete for any type of construction have led to the requirement of properties like greater fluidity, self-compact ability, greater strength, more durability, better serviceability and greater life of concrete structures. Manual placing and inadequate consolidation have led to the need for the development of concrete with high fluidity and no segregation. This led to the development of engineered concrete that addresses these requirements known as Self Compacting Concrete. The concept introduced since 1980 at Japan. To improve durability structure of concrete. Fibers when added to SCC, further enhance the quality of concrete structures. Fibers strengthened self-compacting concrete combines the blessings of SCC sparkling nation and enhance the fine of fibers bolstered concrete inside the harsh country.

Revised Manuscript Received on February 05, 2020.

* Correspondence Author

Deepak G Appaji*, Research Scholar, Civil Engineering department U.V.C.E, Bangalore University, J.B.Campus, Bangalore 560056 e-mail: deepak.g.1013@gmail.com

Chethan K, Assistant Professor, Civil Engineering department U.V.C.E, Bangalore University, J.B.Campus, Bangalore 560056

(C) The Authors. Published by Blue Eyes Intelligence Engineering and Sciences Publication (BEIESP). This is an open access article under the CC BY-NC-ND license (http://creativecommons.org/licenses/by-nc-nd/4.0/)

\section{REVIEW OF LITERATURE}

Okamura and Ozawa (1995), they investigated a simple mix equivalent system for Self compacting concrete. Their studies indicated that coarse and quality aggregate are constant, so that self- compact capacity can be accomplished without difficulty via fix the water to powder ratio and superplasticizer dosage most effective.

Qadi et al (2011), Their reported study on the ideal polypropylene amount in SCC. The result obtained to suppress spalling when exposed to higher temperatures of 200, 400, and $600^{\circ} \mathrm{C}$ fixed for 2 and 4 hours. It increases in percentages of Polypropylene fibers segregation resistance decreases. It includes Polypropylene fibers at various dosages does not alter the remaining compressive strength $\left(200^{\circ} \mathrm{C}\right.$ and $400^{\circ} \mathrm{C}$ ), while they substantially enhance the extra compressive strength of concretes after exposure to $600^{\circ} \mathrm{C}$. Dosage of $0.05 \%$ Polypropylene fibers by volume can be described as the ideal amount of Polypropylene fibers to use in concretes due to its exceptional on heating.

Widodo (2012), His conducted research on evaluating fresh and hardened properties of SCC with PP fibers of $0 \%$, $0.05 \%, 0.10 \%$, and $0.15 \%$ volume fraction. The study results show polypropylene fibers influenced to lower the flow ability and passing ability, but it will increase viscosity and segregation resistance of SCC. The study conclude that compressive strength favor to boost when fibers added up to $0.05 \%$ and better splitting tensile strength is witnessed when the fibers are added up to $0.10 \%$. Polypropylene fibers addition also provides positive effects on the impact of resistance.

\section{EXPERIMENTAL PROGRAMME}

The experimental program included the following steps

- The materials were tested for their physical properties.

- Trials mixes using the Okamura method of mix design were executed for the following $2 \mathrm{mix}$ proportions to achieve the final mixes, which satisfies all the workability properties.

MIX -1: SCC containing $100 \%$ cement with $0.5 \%$ fibers. MIX -2: SCC containing 90\% cement $+10 \%$ Silica fume with $0.5 \%$ fibers.

- The specimens were cast and cured for 7 \& 28 days and tested.

- Specimens are subjected to the requisite number of thermal cycles at two different temperatures as given below:

7 days cured specimens -

7 \& 28 thermal cycles@ $100^{\circ} \mathrm{C}$ 


\section{Effect of Elevated Temperatures and Thermal Cycles on Self Compacting Concrete Reinforced with Polypropylene Fibers}

28 days cured specimens -7 \& 28 thermal cycles @ $100^{\circ} \mathrm{C}$

- The change of weight of the specimen after each thermal cycle was recorded.

- After thermal cycles, the specimens were tested to know their strength.

\section{A. Mix Design Procedure}

The study Mix Design states that:

- Coarse aggregate (all particles larger than $4.75 \mathrm{~mm} \&$ smaller than the maximum size of aggregate) is adjusted in the range of solid volume is about $50 \%$ to $60 \%$.

- Fine aggregate (all particles larger than $0.125 \mathrm{~mm} \&$ smaller than $4.75 \mathrm{~mm}$ ) was zippered of mortar volume in range of $40 \%$ to $50 \%$.

- The water to powder ratio optimized in the range of 0.9 to 1.0 (by volume), in accordance with the properties of the powder (that is cement and filler having particles smaller than $0.125 \mathrm{~mm}$ ).

B. Material Properties and Mix Designations

The specific gravity of materials adopted in this and analyzed in Table I

study

Table- I: Specific gravity of materials considered

\begin{tabular}{|c|c|}
\hline Materials & $\begin{array}{c}\text { Specific } \\
\text { gravity }\end{array}$ \\
\hline Coarse Aggregate & 2.65 \\
\hline Fine Aggregate & 2.63 \\
\hline Cement & 3.14 \\
\hline Silica fume & 2.25 \\
\hline Polypropylene fibers & 0.92 \\
\hline
\end{tabular}

The mix designations for the two mixes considered are summarized in Table II

Table- II: Mix designation and Mix details

\begin{tabular}{|c|c|c|c|c|}
\hline $\begin{array}{c}\text { Sl. } \\
\text { No. }\end{array}$ & $\begin{array}{c}\text { Mix } \\
\text { Naming }\end{array}$ & $\begin{array}{c}\text { Cement } \\
\mathbf{( \% )}\end{array}$ & $\begin{array}{c}\text { Silica } \\
\text { Fume } \\
\mathbf{( \% )}\end{array}$ & $\begin{array}{c}\text { Fibers } \\
\mathbf{( \% )}\end{array}$ \\
\hline 1. & AP & 100 & - & 0.5 \\
\hline 2. & BP & 90 & 10 & 0.5 \\
\hline
\end{tabular}

\section{RESULTS \& DISCUSSIONS}

The fresh concrete tests analysis in below table:

Table- III: Fresh properties of Mixes considered

\begin{tabular}{|c|c|c|c|}
\hline \multirow{2}{*}{$\begin{array}{c}\text { Fresh } \\
\text { Concrete } \\
\text { Property/ Test }\end{array}$} & \multicolumn{2}{|c|}{ Mix } & \multirow{2}{*}{$\begin{array}{c}\text { Desired Range as } \\
\text { per } \\
\text { EFNARC(2005) } \\
\text { Guidelines }\end{array}$} \\
\hline & $\mathbf{A P}$ & BP & \\
\hline $\begin{array}{l}\text { Slump } \\
\text { flow(mm) }\end{array}$ & 675 & 660 & $650-800$ \\
\hline J-ring (mm) & 9 & 7 & $0-10$ \\
\hline V-funnel(Sec) & 10 & 11.5 & $6-12$ \\
\hline $\mathrm{L}-\mathrm{Box}\left(\mathrm{H}_{2} / \mathrm{H}_{1}\right)$ & 0.90 & 0.85 & $0.8-1.0$ \\
\hline $\begin{array}{l}\text { U-Box }\left(\mathrm{H}_{1-} \mathrm{H}_{2}\right. \\
\mathrm{mm})\end{array}$ & 23 & 27 & $0-30$ \\
\hline
\end{tabular}

Compressive Strength for 7 and 28days cured specimens after $100^{\circ} \mathrm{C}$ thermal cycles are shown below:

Table- IV: Compressive Strength for 7days cured specimens

\begin{tabular}{|c|c|c|c|}
\hline \multirow{2}{*}{ Mix } & \multicolumn{3}{|c|}{ Compressive Strength (N/mm $\left.\mathbf{m}^{\mathbf{}}\right)$} \\
\cline { 2 - 4 } & \multicolumn{3}{|c|}{ No. of Thermal Cycles } \\
\cline { 2 - 4 } & $\mathbf{0}$ & $\mathbf{7}$ & $\mathbf{2 8}$ \\
\hline AP & 20.14 & 24.29 & 28.44 \\
\hline BP & 28.73 & 38.50 & 39.16 \\
\hline
\end{tabular}

Table-V: Compressive Strength for 28days cured specimens

\begin{tabular}{|c|c|c|c|}
\hline \multirow{2}{*}{ Mix } & \multicolumn{3}{|c|}{ Compressive strength $\left(\mathbf{N} / \mathbf{m m}^{\mathbf{2}}\right)$} \\
\cline { 2 - 4 } & $\mathbf{3}$ & $\mathbf{7}$ & $\mathbf{2 8}$ \\
\cline { 2 - 4 } & $\mathbf{0}$ & 32.58 & 32.58 \\
\hline AP & 31.40 & 32.88 & 37.92 \\
\hline
\end{tabular}

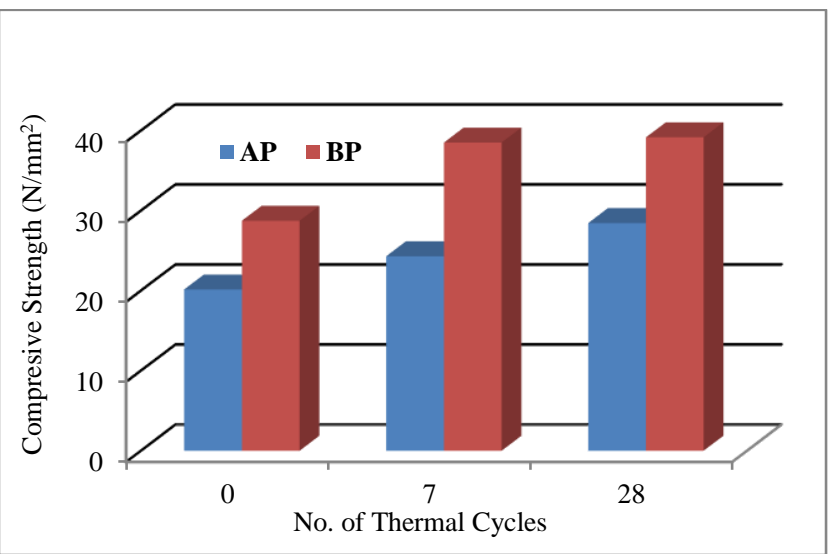

Fig.1. Compressive strength of concrete cubes cured for 7 days subjected to $100^{\circ} \mathrm{c}$ thermal cycles

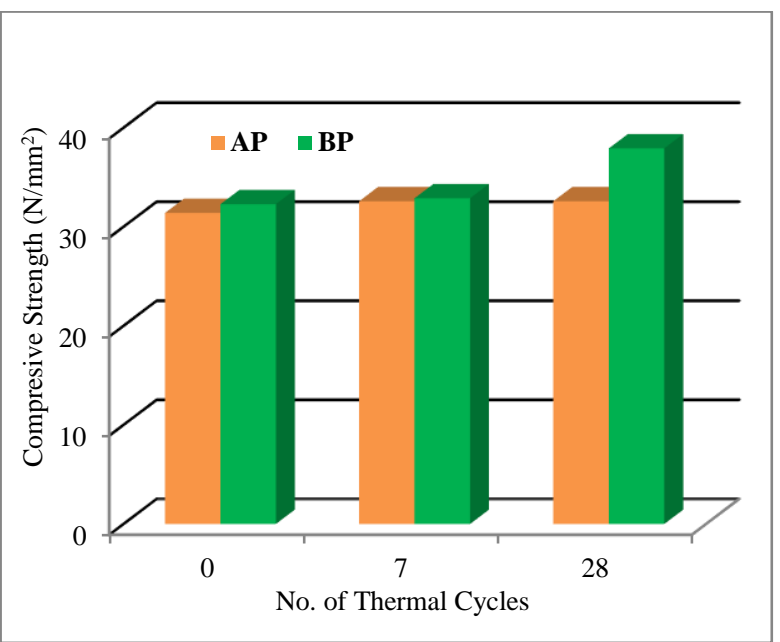

Fig 2. Compressive strength of concrete cubes cured for 28 days subjected to $100^{\circ} \mathrm{C}$ thermal cycles

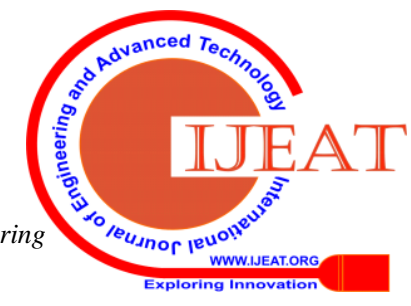


The increasing percentage of compressive strength for AP mix 7 days cured specimen is $20.61 \%$ when it is subjected to 7 days thermal cycle while the corresponding increase is $41.21 \%$ for 28 days' thermal cycle. For BP mix 7 days cured specimens the percentage increase in strength is $34.01 \%$ and $36.30 \%$ for 7 days and 28 days' thermal cycle. Strength for 28 days gradually increase cured AP mix when number of thermal cycles is increased. There is a large increase in strength for 28 days cured BP mix when no. of thermal cycles is increased from 7 days to 28 days which may be attributed to the pozzolanic action at later ages. Flexural Strength for 7 and 28days cured specimens after $100^{\circ} \mathrm{C}$ thermal cycles are presented in Tables VI and VII.

Table-VI: Flexural strength of 7 days cured specimens

\begin{tabular}{|c|c|c|c|}
\hline \multirow{2}{*}{ Mix } & \multicolumn{3}{|c|}{ Flexural Strength $\left(\mathbf{N} / \mathbf{m m}^{\mathbf{2}}\right.$ ) } \\
\cline { 2 - 4 } & \multicolumn{3}{|c|}{ No. of Thermal Cycles } \\
\cline { 2 - 4 } & $\mathbf{0}$ & $\mathbf{7}$ & $\mathbf{2 8}$ \\
\hline AP & 6.83 & 8.75 & 9.33 \\
\hline BP & 7.50 & 8.91 & 9.91 \\
\hline
\end{tabular}

Table-VII: Flexural strength of 28 days cured specimens

\begin{tabular}{|c|c|c|c|}
\hline \multirow{2}{*}{ Mix } & \multicolumn{3}{|c|}{ Flexural Strength $\left(\mathbf{N} / \mathbf{m m}^{\mathbf{2}}\right)$} \\
\cline { 2 - 4 } & \multicolumn{3}{|c|}{ No. of Thermal Cycles } \\
\cline { 2 - 4 } & $\mathbf{0}$ & $\mathbf{7}$ & $\mathbf{2 8}$ \\
\hline AP & 8.25 & 9.33 & 9.58 \\
\hline BP & 8.33 & 9.58 & 9.83 \\
\hline
\end{tabular}

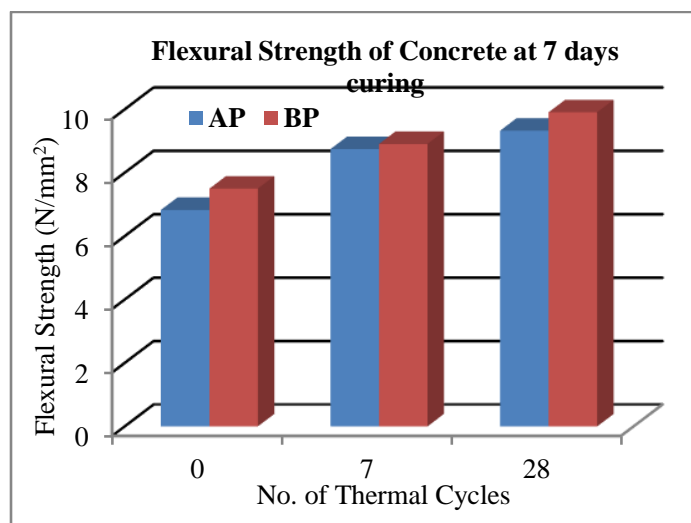

Fig.3. Flexural Strength of concrete prisms cured for 7 days subjected to $100^{\circ} \mathrm{C}$ thermal cycles

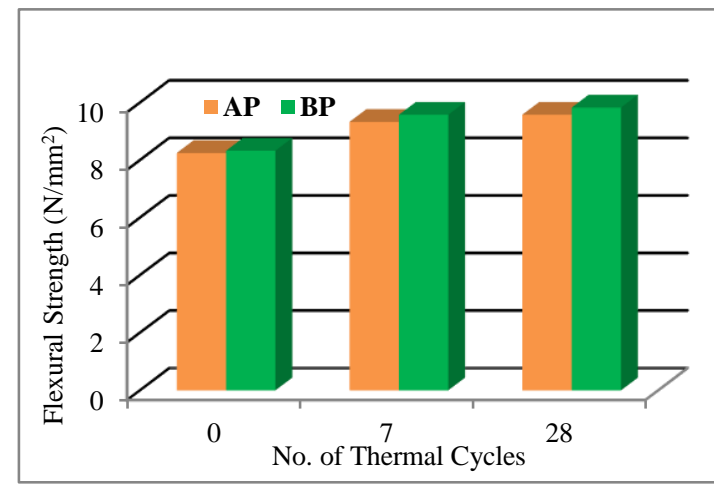

Fig.4. Flexural Strength of Concrete prisms cured for 28 days subjected to $100^{\circ} \mathrm{C}$ thermal cycles.
The increasing percentage of flexural strength for 7 days cured AP mix specimen is $28.11 \%$ and $36.6 \%$ when subjected to 7days and 28 days thermal cycle respectively while the corresponding increase is $13.09 \%$ and $16.12 \%$ for 28 days cured specimen. For BP mix, 7 days cured specimens the percentage increase in strength is $18.8 \%$ and $32.13 \%$ for 7 days and 28 days thermal cycle while it is $15.01 \%$ and $18.01 \%$ for 28 days cured specimen. Percentage reduction in weight for 7 and 28days cured specimens after $100^{\circ} \mathrm{C}$ thermal cycles are presented in Tables VIII and IX

Table-VIII: Percentage reduction in weight of 7 days cured prisms

\begin{tabular}{|c|c|c|c|c|}
\hline \multirow{3}{*}{ Mix } & \multicolumn{4}{|c|}{ \% Reduction in Weight } \\
\hline & \multicolumn{4}{|c|}{ No. of Thermal Cycles } \\
\hline & $\mathbf{0}$ & 7 & 14 & 28 \\
\hline AP & 12.41 & 12.01 & 12.00 & 11.99 \\
\hline BP & 11.76 & 11.49 & 11.49 & 11.49 \\
\hline
\end{tabular}

Table-XI: Percentage reduction in weight of 28 days cured prisms

\begin{tabular}{|c|c|c|c|c|}
\hline \multirow{2}{*}{ Mix } & \multicolumn{4}{|c|}{ \% Reduction in Weight } \\
\cline { 2 - 5 } & $\mathbf{4}$ & $\mathbf{7}$ & $\mathbf{1 4}$ & $\mathbf{2 8}$ \\
\cline { 2 - 5 } & $\mathbf{0}$ & 12.16 & 12.11 & 12.11 \\
\hline AP & 12.35 & 11.46 & 11.46 & 11.42 \\
\hline
\end{tabular}

For 7 and 28 days curing of prisms, there is a decrease in weight of specimens as the thermal cycles increases although the \% reduction in weight is not very appreciable with the increase in thermal cycles.

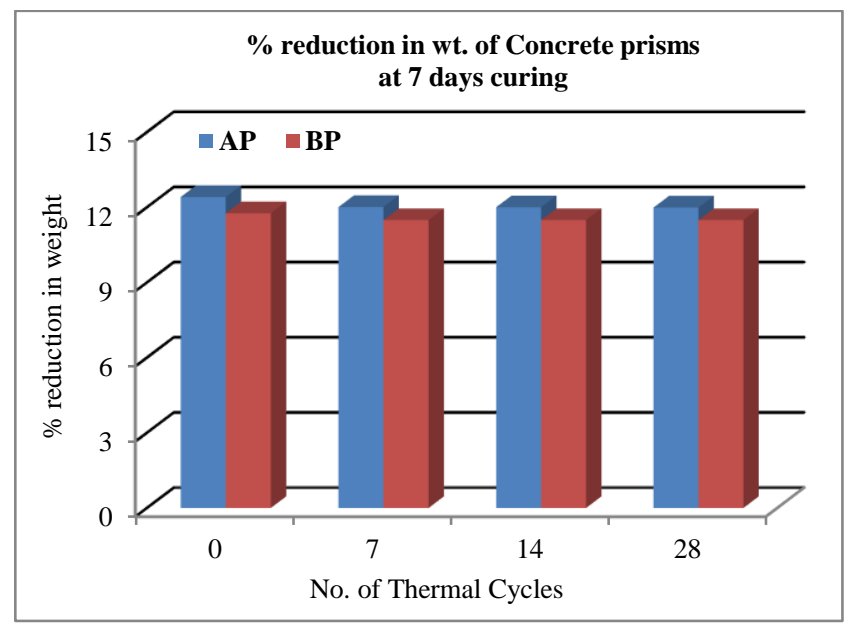

Fig.5. Percentage reduction of weight in Concrete prisms cured for 7 days subjected to $100^{\circ} \mathrm{C}$ thermal cycles 
Effect of Elevated Temperatures and Thermal Cycles on Self Compacting Concrete Reinforced with Polypropylene Fibers

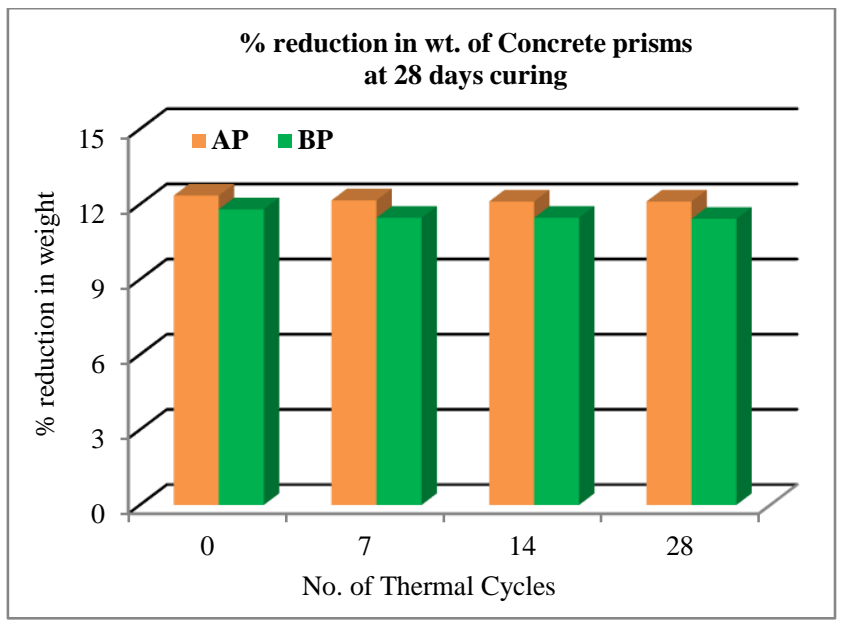

Fig.6. Percentage reduction of weight in Concrete prisms cured for 28 days subjected to $100^{\circ} \mathrm{C}$ thermal cycles

\section{CONCLUSION}

1. Strength increases as thermal cycle increases for both the mixes although the \% increase reduces for 28 days curing.

2. The mix BP with $90 \%$ cement $+10 \%$ Silica Fume has shown higher flexural and compressive strength.

3. The weight of the specimens decreases with the increase in number of thermal cycles and temperature. The percentage reduction in weight is more for specimens cured for 28 days compared to 7 days of cured specimens.

\section{ACKNOWLEDGMENT}

We sincerely thank and acknowledge UVCE, Bangalore University, Bangalore for the Successful completion of this study.

\section{REFERENCES}

1. Okamura H and Ozawa K. (1995). Mix design for self-compacting concrete. Concrete Library of Japanese Society of Civil Engineers, (25),107-120.

2. Rao,srinivasa.K and Potha Raju,M (2004).A study on the variation of compressive strength of high strength concrete at elevated temperatures.25 - 26, August.

3. Kulkarni,D B and Patil,S N (2011).Comparative Study of Effect of Sustained High Temperature on strength Properties of Self Compacting Concrete and Ordinary Conventional Concrete. International Journal of Engineering and Technology,3(2), 106-118.

4. Arabi N S AL Qadi Bin Nasharuddin Kamal Mustapha Bin, Sivakumar Naganathan, and Qahir N. S. Al-Kadi (2011). Effect of polypropylene fibers on fresh and hardened properties of Self Compacting Concrete at elevated temperature. Australian Journal of Basic and Applied Sciences,5,(10),378-384.

5. Widodo,Slamet (2012). Fresh and hardened properties of Polypropylene fiber added Self-Consolidating Concrete. International Journal of Civil and Structural Engineering,3,(1),112-116.

6. EFNARC(2005). European guidelines for self-compacting concrete Specification, Production, and Use.

7. Mundle,H.G (2014).Variation in the strength of concrete subjected to High temperature. International Journal of Research in Engineering \& Technology,2,(2),149-154.

8. Benaicha M, Jalbaud O, A. Hafidi Alaoui A and Burtschell,Y(2013): Rheological and Mechanical Characterization of Fibers-Reinforced Self-Compacting Concrete. International Journal of Engineering and Innovative Technology,2,(7),112-119.

9. Specification for coarse and fine aggregate from a natural source for concrete, IS 383-1970.Retirevied from 12/03/2019.
10. Methods of tests for strength of concrete, IS 516-1959.

11. Methods of physical tests for aggregates for concrete, IS 2386-1963.

12. Methods of physical tests for hydraulic cement, IS 4031-1996.

13. Specification for 53 grades OPC, IS 12269-1987.

\section{AUTHORS PROFILE}

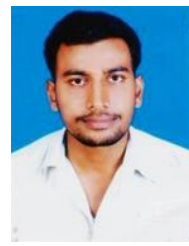

Deepak. G. Appaji, Research Scholar, Civil Engineering department U.V.C.E, Bangalore University, J.B.Campus, Bangalore560056 e-mail: deepak.g.1013@gmail.com

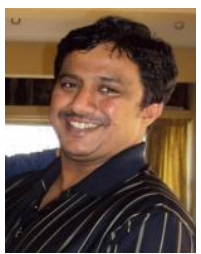

Dr.Chethan. K, Assistant Professor, Civil Engineering department U.V.C.E, Bangalore University, J.B Campus, Bangalore -560056 